\title{
Impact of habitat variability on growth dynamics of Bergenia ciliata (Haw.) Sternb. along an altitudinal gradient in Kashmir Himalaya, India
}

\author{
Junaid A. Magray ${ }^{1}$, Shabir A. Zargar ${ }^{2}$, Tajamul Islam ${ }^{1^{\star}}$, Irshad A. Nawchoo ${ }^{1}$ \\ ${ }^{1}$ Plant Reproductive Biology, Genetic Diversity and Phytochemistry Research Laboratory, Department of Botany, University of Kashmir, Srinagar 190 \\ 006, J \& K, India \\ ${ }^{2}$ Department of Botany, University of Kashmir, Srinagar 190 006, J \& K, India \\ *Email: islamtajamul66@gmail.com
}

\section{Open ACCESS}

\section{ARTICLE HISTORY}

Received: 02 July 2021

Accepted: 24 October 2021

Available online

Version 1.0 (Early Access): 20 November 2021 Version $2.0: 01$ January 2022

\section{Check for updates}

Additional information

Peer review: Publisher thanks Sectional Editor and the other anonymous reviewers for their contribution to the peer review of this work.

Reprints \& permissions information is available at https://horizonepublishing.com/ journals/index.php/PST/open_access_policy

Publisher's Note: Horizon e-Publishing Group remains neutral with regard to jurisdictional claims in published maps and institutional affiliations.

Indexing: Plant Science Today, published by Horizon e-Publishing Group, is covered by Scopus, Web of Science, BIOSIS Previews, Clarivate Analytics, etc. See https:// horizonepublishing.com/journals/index.php/ PST/indexing_abstracting

Copyright: ( $)$ The Author(s). This is an openaccess article distributed under the terms of the Creative Commons Attribution License, which permits unrestricted use, distribution and reproduction in any medium, provided the original author and source are credited (https://creativecommons.org/licenses/ by $/ 4.0 /$ )

\section{CITE THIS ARTICLE}

Magray J A, Zargar S A, Islam T, Nawchoo I A. Impact of habitat variability on growth dynamics of Bergenia ciliata (Haw.) Sternb. along an altitudinal gradient in Kashmir Himalaya, India. Plant Science Today. 2022;9 (1):144-149. https://doi.org/10.14719/ pst.1367

\begin{abstract}
Bergenia ciliata (Haw.) Sternb. is an important medicinal plant of the Himalayan region. Phenotypic attributes of a particular plant species varies along different altitudes in order to adapt and to overcome the changeable and stressful conditions. A number of environmental factors such as mean temperature, precipitation, soil characteristics, radiation intensity etc. changes with altitudinal gradient and thereby affect the morphological pattern of a plant species. The present study was undertaken to reveal the impact of the elevational gradient and habitat variability on the morphological features of the selected species. Under different environmental conditions the species exhibited enormous variability in its phenotypic traits. The plants were shorter at high altitude site, Gulmarg while the plants of low altitude site, Kashmir University Botanical Garden (KUBG) were taller and more vigorous. A significant decrease in the plant height, inflorescence length, leaf length, leaf breadth and petiole length occurred with increasing altitude. Principal component analysis (PCA) revealed that the habitat of KUBG and Ferozpora (Tangmarg) proved relatively better for the growth of $B$. ciliata. The regression analysis revealed positive correlation between plant height and traits like inflorescence length, leaf length, leaf number and thus predicting a direct impact of plant height on other traits. Our findings present a comprehensive account on the variability of phenotypic characteristics, in relation to the environmental conditions of this valuable medicinal plant species.
\end{abstract}

\section{Keywords \\ Himalayan region, habitat variability, altitudinal gradient, phenotypic attributes}

\section{Introduction}

Bergenia ciliata (Haw.) Sternb. (family Saxifragaceae) is perennial herbs upto $50 \mathrm{~cm}$ tall, succulent, distributed in temperature Himalayan region (from Kashmir to Nepal) (1). This family comprising of 30 genera and 580 species mostly distributed in the cold and temperate regions (2). The genus Bergenia comprises of 6 species distributed in the temperate Himalayas and Central and East Asia. Bergenia ciliata is commonly known as hairy Bergenia and is a found throughout temperate Himalaya region (from Kashmir, Nepal, southeast Tibet to Afghanistan) (3) at an altitude of 800-3000 m asl (3, 4). In Jammu and Kashmir, B. ciliata is locally known as Zakhmehayat (5), Batweyaa, Pashanbhed (6). The variability in growth and position of resource accumulating parts such as rhizomes, leaves are crucial for adjust- 
ment of plants to resource accessibility (7). Under severe conditions, plants can adjust themselves either by adapting genetically to the local environmental conditions or by exhibiting phenotypic plasticity (8). For plants phenotypic plasticity is of utmost importance as they are immobile and have to thrive in the fluctuating local conditions. It also acts as a window to adjust rapidly to the changing environmental conditions $(9,10)$. At higher altitudes phenotypic plasticity is believed to occur more regularly, enabling the alpine plants to adapt to the temporally variable environment $(11,12)$. Although plasticity is beneficial but can have neutral or negative impacts on fitness of plant species (13). Plants alter important physiological processes such as photosynthetic rates, gaseous exchange (14) and morphological traits $(15,16)$ in response to environmental factors. Decrease in plant length along altitudinal gradient is the most visible change in plant morphology (17).

Bergenia ciliata is an important medicinal plant of western Himalaya, used in treating various diseases (18). The plant species shows many important biological activities such as antioxidant, anti-inflammatory, antitussive, antiviral, antiulcer, hypoglycemic and toxicological activities $(19-21)$. It is a potent source of flavonoids, saponins, alkaloids, amino-acids and carbohydrates (22). Bergenin and its glycosides, $(+)$-Catechin, Gallic acid and leucocyanidin, Paashaanolactone, $\beta$-Sitosterol -Afzelechin are some of the important phytochemicals of B. ciliata (23). Rhizome and root is an effective to combat chronic venereal diseases (4). The plant species is commonly found growing in moist and shady slopes particularly on rock crevices (24). Taxonomically, this plant species is a large scrambling shrubs with thick and fleshy rhizome, growing upto $0.31 \mathrm{~m}-1.0 \mathrm{~m}$ in height. Leaves are simple with ciliated margins. The height and branching pattern, however depends upon the genetic makeup and environmental factors of a particular site (Phenotype $=$ Genotype $\times$ Environment) (25). The scape is stout, having pentamerous corymbose inflorescence. Sepals 5 (gamosepalous), petals 5 (polypetalous), stamens are 10 in number (5 larger and 5 smaller), pollen tri colpate, smooth. Fruit is a round shaped capsule containing numerous seeds. Seed are minute, elongated smooth and dark brown to blackish in colour. The flowering and fruiting period of $B$. ciliata extends from February to August $(24,26)$. The present study was carried out to understand degree of variation in phenotypic traits along the altitudinal gradient. This study aimed at formulating strategies for cultivation and sustainable use of wild populations and to find the environments that are most suitable and prolific for the growth of $B$. ciliata.

\section{Materials and Methods}

The present study involved the use of robust methods and approaches in the field (both in control and natural habitats) and laboratory to monitor, record and understand the phenotypic variability and reproductive strategies of the species. The data on various morphometric characters for revealing the aspects of the phenotypic variability were recorded from March 2015 to October 2016.

\section{Survey, collection and documentation}

Different habitats of Kashmir Himalaya (India) were extensively explored and surveyed to select the specific study sites across this region. In order to study the variability in phenotypic characteristics of $B$. ciliata along the altitudinal gradient, three sites (populations) were selected along with a control site at Kashmir University Botanical garden (KUBG). The map (Fig. 1) shows the

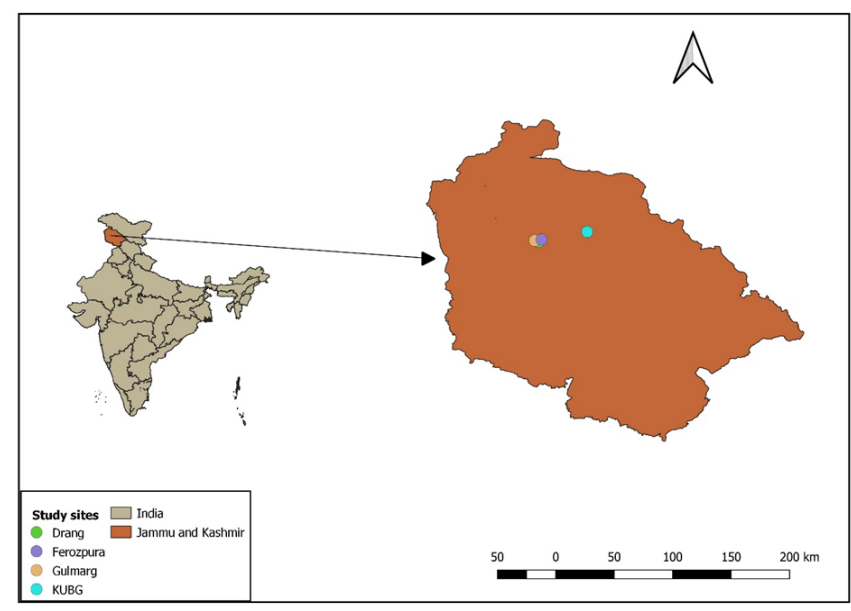

Fig. 1. Map showing study sites of Bergenia ciliata (Haw.) Sternb. in Kashmir valley. (QGIS 3.16).

geographical location of selected sites. During the present study, the marked individuals of selected plant species across different study sites were monitored on regular basis from March 2015 to October 2016. Geocoordinates (latitude and longitude) along with altitude and also the habitat of four study sites are listed in Table 1. Plant samples (10 plants) from each site were collected at mature, flowering stage. The vegetative propagules of selected plant species were transplanted in the KUBG (control site) to study the morphological variations.

Table 1. Geo-coordinates and habitat characteristics of the selected sites

\begin{tabular}{|c|c|c|c|c|c|}
\hline $\begin{array}{l}\text { Sl. } \\
\text { No. }\end{array}$ & Location & $\begin{array}{l}\text { Altitude } \\
\text { (m asl) }\end{array}$ & $\begin{array}{l}\text { Latitude }(N) \text { and } \\
\text { Longitude }(E)\end{array}$ & Habitat & Threat Factor \\
\hline 1. & Gulmarg & 2590 & $\begin{array}{l}34^{\circ} 02^{\prime} 54.4^{\prime \prime} \mathrm{N} \\
74^{\circ} 20^{\prime} 49.8^{\prime \prime} \mathrm{E}\end{array}$ & Moist Open Slope & Over exploitation, overgrazing, landslide \\
\hline 2. & Drang & 2235 & $34^{\circ} 2^{\prime} 87.0^{\prime \prime} \mathrm{N}$ & Sunny to partly shady Slope & $\begin{array}{l}\text { Over exploitation, overgrazing, landslide and habi- } \\
\text { tat destruction }\end{array}$ \\
\hline 3. & $\begin{array}{l}\text { Ferozpora } \\
\text { (Tangmarg)* }^{\star}\end{array}$ & 2120 & $34^{\circ} 3^{\prime} 22.6^{\prime \prime} \mathrm{N}$ & Shady slope & $\begin{array}{l}\text { Over exploitation, overgrazing, landslide and habitat de- } \\
\text { struction. }\end{array}$ \\
\hline
\end{tabular}

*KUBG - Kashmir University Botanical Garden. 


\section{Species morphology and phenotypic variability}

The selected sites were visited continuously at regular intervals of 10 days following standard procedures. All the parameters including morphological traits, habitat type, phytosociology, breeding behaviour and collection of plant samples were recorded at the peak flowering stage of the plant. The plants were analyzed for morphological traits like plant height, number of leaves per plant, mean leaf length per plant, mean leaf breadth per plant, mean petiole length per plant, rhizome length, root length and inflorescence length.

Statistical analysis such as mean, standard Deviation, linear regression for understanding correlation between phenotypic traits across altitudinal gradient to recognize the most suited growth sites of the species, and PCA (Principal component analysis) for analyzing phenotypic traits in relation to different habitat conditions were carried out using Origin Pro 2019b 64 bits software. From each population, data was recorded for 10 plants for comparing the variability in phenotypic characteristics. The photographs were clicked using Samsung mobile having 16 mpxl camera.

\section{Results and Discussion}

Plants and environment have an intricate relationship, a range of environmental factors and stresses challenge the plant to adapt and survive with increase in altitudinal gradient. In order to compete and overcome these stress conditions plants alter their biochemical and morphological attributes $(25,27)$. The disparity in phenotypic characters with varying altitude indicates plasticity and evolutionary changes in these traits, influencing performance and survival of populations existing across altitudinally or climatically variable conditions (28).

Bergenia ciliata exhibits a significant variability in its phenotypic traits under different environmental conditions. This phenotypic variability was observed in four selected sites viz. Gulmarg (2590 m asl), Drang (2235 m asl), Ferozpora (Tangmarg) (2120 m asl) and Kashmir University Botanical Garden (KUBG) Srinagar (1595 m asl) as a control site. The morphological traits that were assessed for phenotypic variability are plant height, number of leaves, mean leaf length, mean leaf breadth, mean petiole length, rhizome length, root length and inflorescence length per plant (Table 2). Fig. 2 shows the morphological features of $B$. ciliata. The selected phenotypic traits shows significant varia-
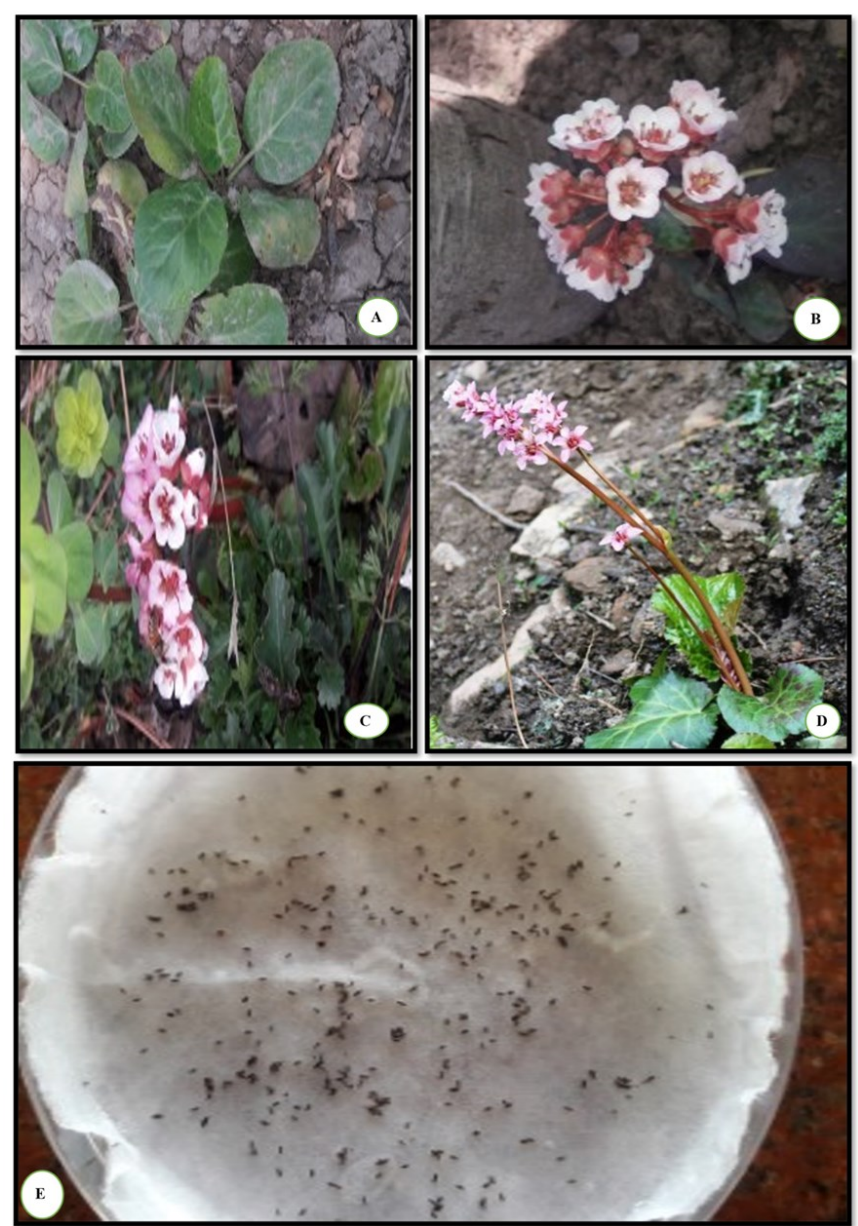

Fig. 2. Bergenia ciliata (Haw.) Sternb. A. habit; B - C. inflorescence; D. habitat; E. seeds.

bility along with altitudinal gradient. The plant height ranges from $9.97 \pm 4.33$ to $42.57 \pm 14.86 \mathrm{~cm}$, number of leaves per plant are $3.00 \pm 0.81$ to $4.0 \pm 1.24 \mathrm{~cm}$. The mean leaf length per plant is $6.29 \pm 1.02$ to $13.27 \pm 4.05 \mathrm{~cm}$. The mean leaf breadth per plant was $3.48 \pm 1.07$ to $8.96 \pm 2.96 \mathrm{~cm}$ and mean petiole length per plant turned out to be $1.99 \pm 0.44$ to $4.46 \pm 2.14 \mathrm{~cm}$. The rhizome length ranged from $4.89 \pm 1.10$ to $5.73 \pm 1.74 \mathrm{~cm}$. The root length ranges from $13.54 \pm 4.92$ to $17.21 \pm 5.53 \mathrm{~cm}$ whereas inflorescence length turned out to be $5.26 \pm 2.30$ to $24.21 \pm 7.28 \mathrm{~cm}$. Most of the phenotypic traits showed a negative correlation with the altitude i.e. they depicted a decreasing trend with increasing altitude.

Morphological traits analyzed vary significantly across the selected populations, viz., Gulmarg, Drang and Ferozpora (Tangmarg) and KUBG. The plant height varies across the different populations. There is an increase in the height of plant in shady environment as seen in site

Table 2. Phenotypic variability of $B$. ciliata across the different study sites

\begin{tabular}{|c|c|c|c|c|}
\hline \multirow{2}{*}{ Phenotypic traits } & \multicolumn{4}{|c|}{ Populations } \\
\hline & Gulmarg* & Drang & Ferozpora (Tangmarg) & KUBG* \\
\hline Plant height $(\mathrm{cm})$ & $9.97 \pm 4.33^{\star \star}$ & $13.10 \pm 3.89$ & $13.88 \pm 4.05$ & $42.57 \pm 14.86$ \\
\hline Mean leaf Length per plant $(\mathrm{cm})$ & $6.29 \pm 1.02$ & $8.34 \pm 1.16$ & $8.42 \pm 1.29$ & $13.27 \pm 4.05$ \\
\hline Mean leaf breadth $(\mathrm{cm})$ & $3.48 \pm 1.07$ & $5.53 \pm 1.38$ & $5.60 \pm 1.08$ & $8.96 \pm 2.96$ \\
\hline Mean petiole length $(\mathrm{cm})$ & $1.99 \pm 0.44$ & $2.24 \pm 0.57$ & $2.33 \pm 0.72$ & $4.46 \pm 2.14$ \\
\hline Rhizome length $(\mathrm{cm})$ & $4.89 \pm 1.10$ & $5.65 \pm 1.51$ & $5.85 \pm 1.63$ & $5.73 \pm 1.74$ \\
\hline Root length $(\mathrm{cm})$ & $13.54 \pm 4.92$ & $18.01 \pm 4.24$ & $18.13 \pm 4.36$ & $17.21 \pm 5.56$ \\
\hline Inflorescence length $(\mathrm{cm})$ & $5.26 \pm 2.30$ & $8.33 \pm 2.05$ & $9.24 \pm 2.11$ & $24.21 \pm 7.28$ \\
\hline
\end{tabular}

*Kashmir University Botanical Garden, ${ }^{\star \star}$ Mean \pm SD 
Ferozpora (Tangmarg) compared to the plants exposed to direct sun light. As compared to the natural populations, plants transplanted at control site (KUBG) exhibited the highest values for nearly all the morphological characters. Dendrogram showing clustering of study sites, exhibits similar phenotypic variations in different traits of plant species as shown in Fig. 3. The variations in phenotypic traits

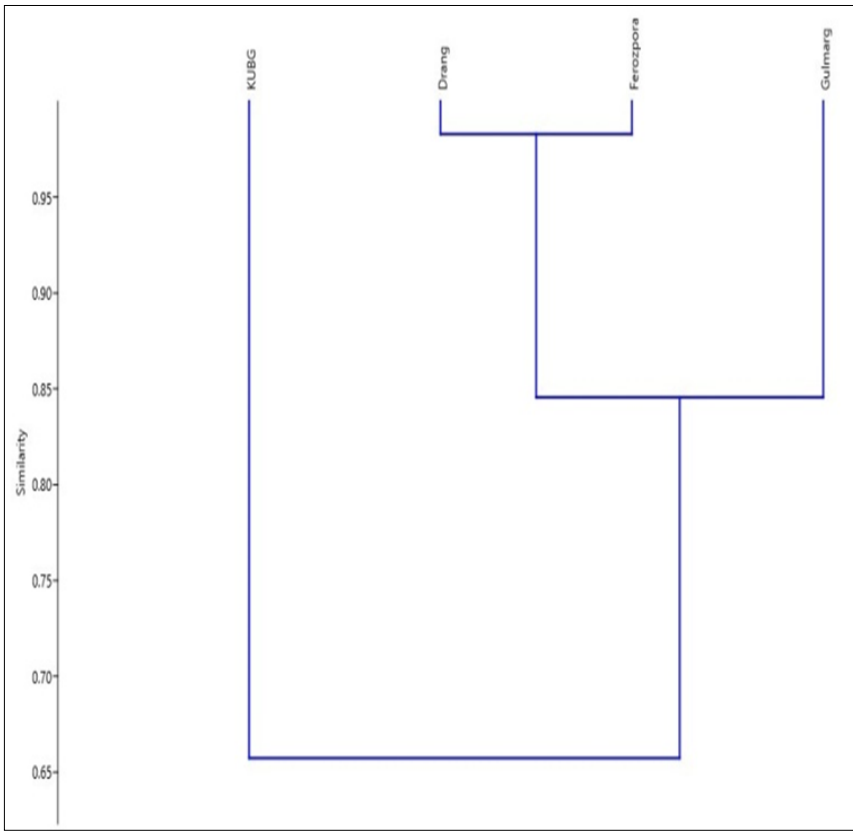

Fig. 3. Dendrogram (cluster analysis) showing the similarity among different selected study sites.

across natural populations and KUBG were very significant while as Drung and Ferozpora (Tangmarg) were not very significant which may be attributed to least differences in their overall environmental conditions. A positive correlation between plant height and inflorescence length $\left(r^{2}=0.9674\right)$, leaf length and plant height $\left(r^{2}=0.8803\right)$, leaf number and plant height $\left(r^{2}=0.0492\right)$ were observed as shown in Fig. 4 (A-H). In Fig. 5, Principle Component Analysis (PCA) reveals that the population growing at higher alti-

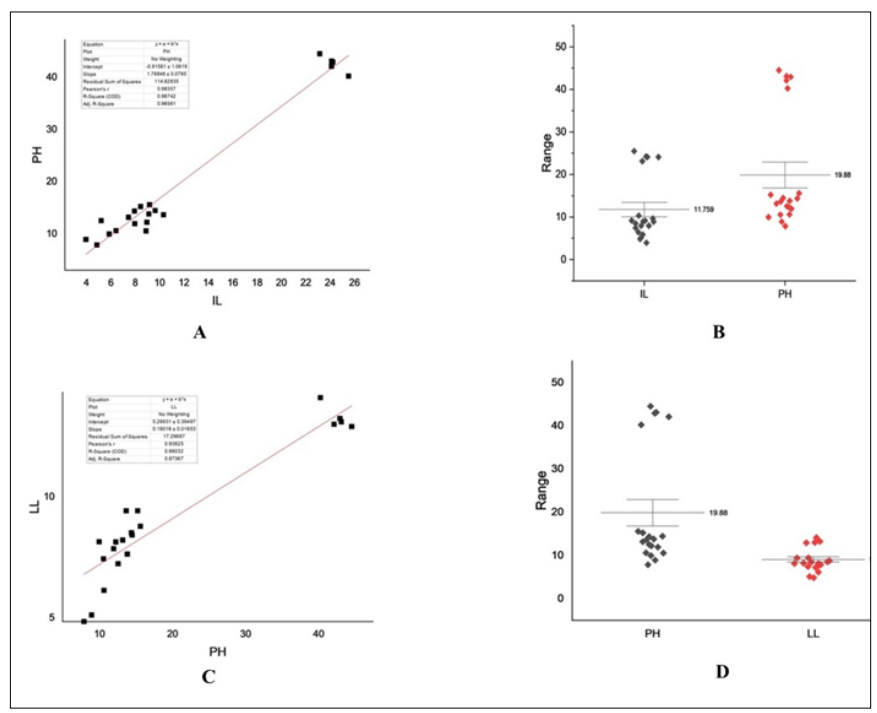

Fig. 4 (A-D). Regression analysis and scale interval between various morphological traits of Bergenia ciliata (Haw.) Sternb.

tude (Gulmarg) shows decrease in size of phenotypic traits and thus separated the population of Gulmarg from the other populations. However the population growing at

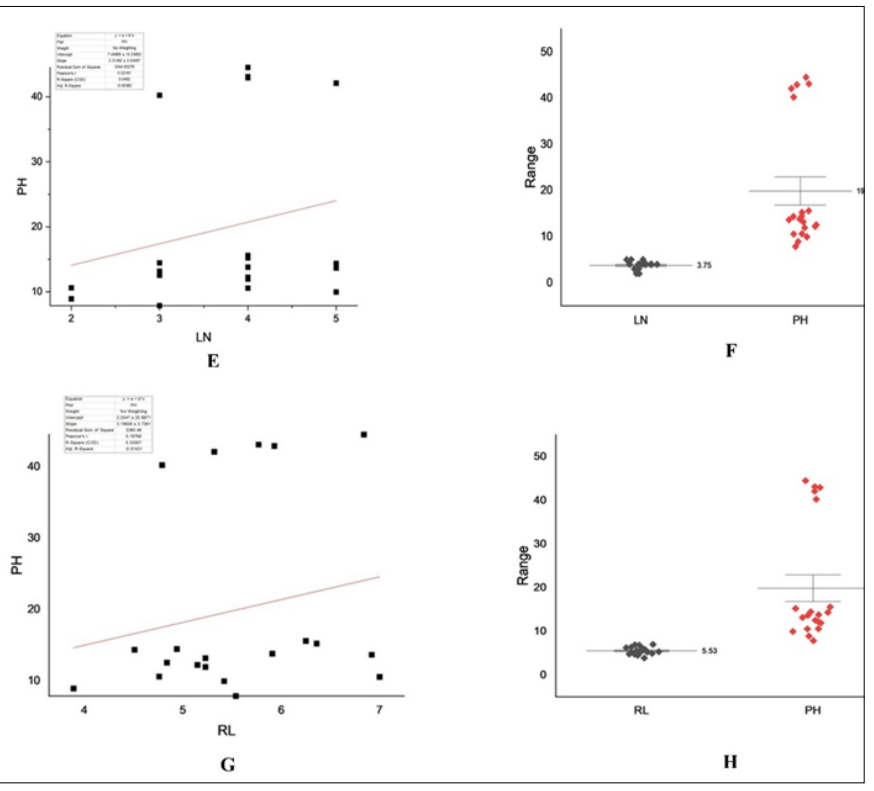

Fig. $4(\mathrm{E}-\mathrm{H})$. Regression analysis and scale interval between various morphological traits of Bergenia ciliata (Haw.) Sternb.

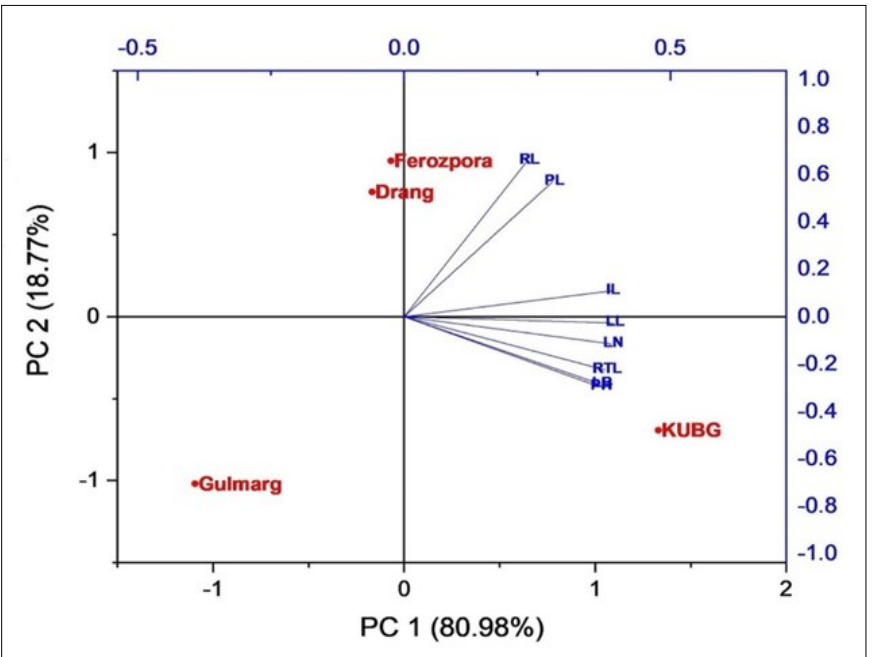

Fig. 5. Principal Component Analysis (PCA) of morphological characteristics of Bergenia ciliata (Haw.) Sternb. across the different study sites. PH. plant height; LB. leaf breadth; RL. rhizome length; PL. petiole length; IL. inflorescence length; $L L$. leaf length; LN. leaf number; RTL. root length.

Ferozpora (Tangmarg) possesses the average plant height of $13.88 \pm 4.05 \mathrm{~cm}$ in comparison with the populations growing at Drang and Gulmarg having the plant height of $13.10 \pm 3.89 \mathrm{~cm}$ and $9.97 \pm 4.33 \mathrm{~cm}$, respectively. The scale interval (Fig. 6) shows the mean and range of selected phe-

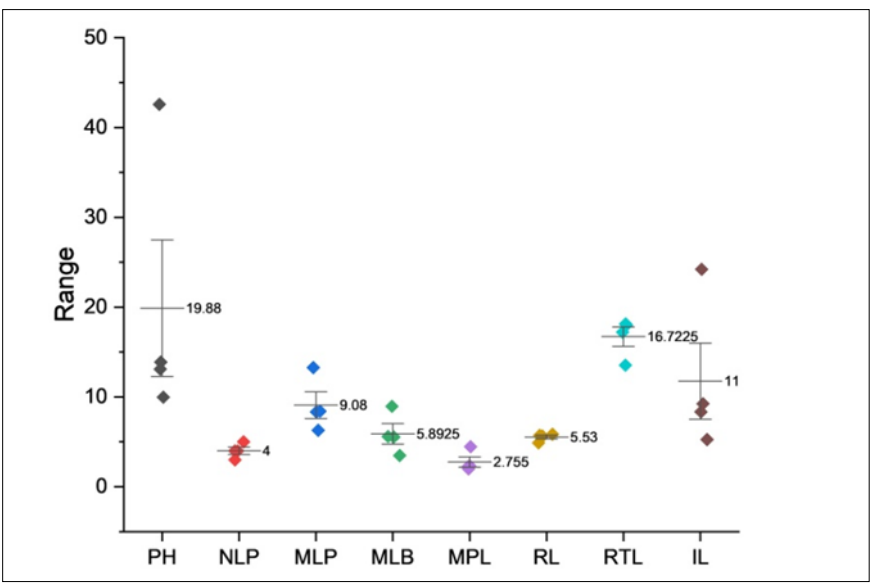

Fig. 6. Scale interval showing the mean and range of all phenotypic traits of Bergenia ciliata (Haw.) Sternb. 
notypic traits. The shady environment favors the plant species to attain the maximum height as it has to compete for light. This supports the findings of (29). Similar findings were reported by several workers (30-34) stated that the decrease in plant height along with altitudinal gradient is advantageous for the species as it prevents the plant from strong winds. There is increase in leaf dimensions in plants growing at lower altitudes $(8.42 \pm 1.29)$ as compared to those growing at higher altitudes $(6.29 \pm 1.02)$. The obtained results are in conformity with those of (35) who reported that leaves dimensions generally decrease with increase in altitude.

\section{Conclusion}

The present study revealed that Bergenia ciliata growing at different altitudes exhibited differences in plant morphology, architecture and reproductive ecology. The results depicted a wide range of suitable habitats for the growth of $B$. ciliata. The species exhibits significant phenotypic variability in morphological traits i.e., plant height, number of leaves per plant, rhizome length inflorescence length etc. in natural as well as transplant populations along altitudinal gradient. It can be inferred from the present study that variation in environmental conditions proved to have an enormous impact on the growth dynamics and development of $B$. ciliata. It can be suggested from the present study that 7 . the plants growing at low altitudes were comparatively much more diverse and vigorous in respect of the various morphological features. There is variability in the morphological attributes such as height, leaf number, inflorescence length etc. and seed set along the altitudinal gradient. These variations in morphological parameters and seed formation may be due to the impact of various environmental factors, seasonal variations and competition for resources or herbivory.

\section{Acknowledgements}

We are highly thankful to head Department of Botany, University of Kashmir for providing feasible facilities to carry out this work. We would also provide warm gratitude to all the scholars of RPGBL for providing necessary comments about the manuscript. We would like to thank Ishfaq UI Rehman for giving valuable suggestions about the manuscript .

\section{Authors contributions}

This work was carried out in collaboration between the authors. Author JAM collected the primary data and wrote the first draft of manuscript and. Author SAZ edited the first draft of manuscript. Author TI prepared map and managed the analysis of the data. Author IAN edited and designed the final draft of manuscript. All authors read and approved the final manuscript

\section{Compliance with ethical standards}

Conflict of interest: Authors declare that there is no com- peting interest.

Ethical issues: None.

\section{References}

1. Bhakuni DS, Bittner M, Marticorena C, Silval M, Weldt E. Screening of Chilean plants for antimicrobial activity. Lloydia. 1974;37:621.

2. Ahmad M., Butt, MA, Zhang G, Sultana, S., Tariq A, Zafar M. Bergenia ciliata: a comprehensive review of its traditional uses, phytochemistry, pharmacology and safety. Biomed. Pharmacother. 2018;97:708-21.

3. Ruby KM, Chauhan R, Sharma S, Dwivedi J. Polypharmacological activities of Bergenia species. Int J Pharm Sci Rev Res. 2012;13 (1):100-10.

4. Pokhrel P, Parajuli RR, Tiwari AK, Banerjee J. A short glimpse on promising pharmacological effects of Begenia ciliata. J App Pharm Sci. 2014;2(1):01-06.

5. Khan M, Kumar S, Hamal IA, Koul S. Wild edible plants of Sewa catchment area in Northwest Himalaya. J Plant Dev. 2009;1(12):1-7.

6. Jan HA, Sher H, Rahman IU, Hussain W, Abbasi MA, Bussmann RW, Paniagua-Zambrana NY. Bergenia ciliata Sternb. Saxifragaceae. In: Kunwar R.M., Sher H., Bussmann R.W. (eds) Ethnobotany of the Himalayas. Ethnobotany of Mountain Regions. Springer, Cham. 2021; pp. 1-15. https://doi.org/10.1007/978-3-030-455972_36-1

7. Sattarian A, Akbarian MR, Zarafshar M, Bruschi P, Fayyaz P. Phenotypic variation and leaf fluctuating asymmetry in natural populations of Parrotia persica (Hamamelidaceae), an endemic species from the Hyrcanian forest (Iran). Acta Bot Mex. 2011;(97):6581.

8. Becker U, Colling G, Dostal P, Jakobsson A, Matthies D. Local adaptation in the monocarpic perennial Carlina vulgaris at different spatial scales across Europe. Oecologia. 2006;150(3):506-18.

9. Sultan SE. Phenotypic plasticity for plant development, function and life history. Trends Plant Sci. 2000;5(12):537-42.

10. Hoffmann AA, Sgrò CM. Climate change and evolutionary adaptation. Nature. 2011;470(7335):479-85.

11. Stöcklin J, Kuss P, Pluess AR. Genetic diversity, phenotypic variation and local adaptation in the alpine landscape: case studies with alpine plant species. Bot Helv. 2009;119(2):125-33.

12. Pluess AR, Frei E, Kettle CJ, Hahn T, Ghazoul J. Plant growth and fitness of Scabiosa columbaria under climate warming conditions. Plant Ecol Divers. 2011;4(4):379-89.

13. Ghalambor CK, McKay JK, Carroll SP, Reznick DN. Adaptive versus non囚adaptive phenotypic plasticity and the potential for contemporary adaptation in new environments. Funct Ecol. 2007;21(3):394-407.

14. Körner C. The use of 'altitude'in ecological research. Trends in ecology and evolution. 2007 Nov 1;22(11):569-74.

15. Ma M, Zhou X, Wang G, Ma Z, Du G. Seasonal dynamics in alpine meadow seed banksalong an altitudinal gradient on the Tibetan Plateau. Plant Soil. 2010;336(1):291-302.

16. Phillips NC, Drost DT, Varga WA, Shultz LM. Demography, reproduction and dormancy along altitudinal gradients in three intermountain Allium species with contrasting abundance and distribution. Flora Morphol. 2011;206(2):164-71.

17. Körner C, Neumayer M, Menendez-Riedl SP, Smeets-Scheel A. Functional morphology of mountain plants. Flora. 1989;182(56):353-583.

18. Farooquee NA, Majila BS, Kala CP. Indigenous knowledge systems and sustainable management of natural resources in a high 
altitude society in Kumaun Himalaya, India. J Hum Ecol. 2004;16 (1):33-42.

19. Sinha S, Murugesan T, Maiti K, Gayen JR, Pal B, Pal M, Saha BP. Antibacterial activity of Bergenia ciliata rhizome. Fitoterapia. 2001;72(5):550-52.

20. Mazhar-Ul-Islam IA, Usmanghani K, Shahab-ud-Din AA. Antifungal activity evaluation of Bergenia ciliata. Pak J Pharmacol. 2002;19(2):1-6.

21. Zafar R, Ullah H, Zahoor M, Sadiq A. Isolation of bioactive compounds from Bergenia ciliata (Haw.) Sternb rhizome and their antioxidant and anticholinesterase activities. BMC Complement Altern Med. 2019;19(1):1-13.

22. Sultana S, Akram M, Asif HM, Akhtar N. Complementary and alternative approaches to treat peptic ulcer. Int Res J Pharm. 2014;5 (5):353-59.

23. Dharmender R, Madhavi T, Reena A, Sheetal A. Simultaneous Quantification of Bergenin, (+)-Catechin, Gallicin and Gallic acid; and quantification of $\beta$-Sitosterol using HPTLC from Bergenia ciliata (Haw.) Sternb. Forma ligulata Yeo (Pasanbheda). Pharm Anal Acta. 2010;1:104.

24. Chowdhary S, Verma KR. Some peculiar structures in Bergenia species growing in Western Himalaya. Nat Sci. 2010;8(6):100-02.

25. Islam T, Wani BA, Nissar S, Majid N, Nawchoo IA, Magray JA. Impact of habitat variability on phenotypic attributes of Hypericum perforatum L. along an altitudinal gradient in Kashmir Himalaya. J Adv Appl Sci Res. 2021;3(1):1-6.

26. Tisdale EW. Vegetational responses following biological control of Hypericum perforatum in Idaho. Northwest Sci. 1976;50:61-75.
27. Ncube B, Finnie JF, Van Staden J. Quality from the field: The impact of environmental factors as quality determinants in medicinal plants. S Afr J Bot.. 2012;82:11-20.

28. Kim E, Donohue K. Demographic, developmental and life history variation across altitude in Erysimum capitatum. J Ecol. 2011;99 (5):1237-49.

29. Abrahamson WG, Gadgil M. Growth form and reproductive effort in goldenrods (Solidago, Compositae). Am Nat. 1973;107 (957):651-61.

30. Billings WD, Mooney HA. The ecology of arctic and alpine plants. Biol Rev. 1968;43(4):481-529.

31. Shah NC, Yadav BB. Behaviour of Aconitum hetrophyllum Wall. (Ativisha) at low altitude. J Res Ind Medicine. 1970;5:119-24.

32. Hickman JC. Environmental unpredictability and plastic energy allocation strategies in the annual Polygonum cascadense (Polygonaceae). J Ecol. 1975;689-701.

33. Körner C, Cochrane PM. Stomatal responses and water relations of Eucalyptus pauciflora in summer along an altitudinal gradient. Oecologia. 1983;66(3):443-55.

34. Siddique MA, Dar NA, Wafai BA, Beigh YS. Reproductive biology of Podophyllum hexandrum Royle (Podophyllaceae) an important, rare and threatened Himalayan medicinal plant. Proc. Natl Acad Sci India. 1997;10-11.

35. Körner C, Bannister P, Mark AF. Altitudinal variation in stomatal conductance, nitrogen content and leaf anatomy in different plant life forms in New Zealand. Oecologia. 1986;69(4):577-88. 